\title{
4 \\ Inter-Asia referencing and shifting frames of comparison
}

\section{Chua Beng Huat}

Even today, in some quarters of academia in Asia, we can still hear laments about the intellectual domination of the West. For example, it has been pointed out that local Asian scholars are often read by Western scholars as though they are anthropological local informants. The substantive local knowledge that Asian scholars generate is then reconfigured as empirical input to concept and theory formation by Western academics (who are consequently depicted by their critics as former and neo-colonisers). This hierarchical division of academic labour therefore recuperates past colonial domination (see also Chapter 2 in this volume). Conversely, scholars in Asia, who are trained in the Euro-American academies, pluck ready-made concepts from existing literature generated in the latter contexts, and apply them to local conditions in Asia. Local complexities often have to be severely trimmed to fit 'neatly' into the selected Euro-American concepts. The richness of the local is sacrificed to reaffirm an idea for which its original context has been erased, abstracted and 'universalised'. According to this logic, if what was found in the United States is also to be found in an Asian location, the universalising claim of a Western-originated concept is thus (re)affirmed. In these instances, intellectual domination is self-inflicted. Both processes - the neo-colonial appropriation of Asian scholarship by Western academics and the uncritical application of Euro-American concepts by scholars in Asia-are unhappy ones. There are, however, strategic reasons 
for such bad practices: both afford a better chance of publication in privileged, internationally refereed journals edited in the West and published by Englishlanguage book publishers with international reach.

Energy is still being spent on contesting this domination through different modes of conceptualising the difference between 'Asia' and the West. Methods of contestation include critiquing Western cultural imperialism, provincialising the West, enunciating a corrective discourse of the local point of view and conceptualisations of different or alternative modernities (Chakrabarty 2000; Gaonkar 2001). Such contests, however, are essentially futile after 200 years of European presence, largely as colonising powers, in Asia. The education undertaken in Western institutions by Asian scholars and the paradigms and concepts from the West cannot be excised from scholarship formation in Asia by Asians. A more fruitful way forward is suggested by Chen Kuan-Hsing (2010). Chen advocates that Asian scholars should multiply their points of reference, especially those in Asia, and treat Euro-America as one reference point equal to other possible points of reference. Aihwa Ong also called for 'inter-referencing' Asia, referring 'broadly to practices of citation, allusion, aspiration, comparison and competition' (2011: 17). In some sense, both suggestions are simply articulating and catching up with the actual practices in governance and enterprise in Asia, as I shall argue in this chapter.

\section{Emerging inter-Asian referencing}

At the beginning of the twenty-first century, Asian studies as a discipline has to confront the palpable rise of capitalism across the region. One of the consequences of this rise, in contrast with the current financial crisis in Europe and the continuing economic depression in the United States, is an increased confidence in the way things are done in Asia. The idea that the nominal West can be a model for or guide to economic development for the future has been displaced and replaced with Asian references in several areas of economic, social and political practice. The earliest example of this referencing of Asia was the case of export-oriented industrialisation.

Export-oriented industrialisation was pioneered by Japan, and was instrumental in the rapid reconstruction of its devastated post-World War II economy, propelling Japan to become the world's second-largest economy by the 1990s. This industrialisation model was replicated by South Korea, Taiwan, Hong Kong and Singapore, in that order, from the mid-1960s, with equally palpable capitalist economic successes. At the academic level, this model has given rise to various conceptual innovations - for example, a Japan-centred theory of 'flying geese', whereby Japan leads the way in labour-intensive export industries. As it moves 
up the technology and capital-intensive industrial chains, it casts off its labourintensive industries to the next set of industrialising economies, which in turn do the same as their respective economies develop: from Japan to South Korea, Taiwan, Hong Kong and Singapore, and subsequently to Indonesia, Thailand and Vietnam, and so on (Ozawa 2005). The developing economies of the last four countries in turn generated conceptual and theoretical work on several fronts: the new international division of labour, the newly industrialising economies and the developmental state.

A more recent development is in the area of urban and regional planning. One defining characteristic of cities in Asia is high population density, which, with a few exceptions, is way beyond the imagination of American and European city dwellers. Densities such as those of Hong Kong, Shanghai and Mumbai are seldom seen in Euro-America. In view of the rapid urbanisation process in all Asian countries, the planning guidelines of European cities - where the old city is retained and new developments can maintain relatively low height and low density - hold no lessons for urban planners in Asia. Increasingly, urban planners in Asia have to turn to urban developments in other Asian locations as models. Singapore, for example, has served as a reference point for many Asian city governors and urban planners, often rhetorically to drive their development plans rather than concretely to 'reproduce' or clone Singapore in their own cities. This was the case with Bangalore looking towards Singapore in the early 2000s (Nair 2005: 123-24). There are, however, instances where practices in Singapore are concretely replicated, such as the attempt to 'green' Dalian City in China (Hoffman 2011: 55-76), and the residential development of Surabaya, Indonesia, where even the statue of the 'founder' of Singapore, Sir Thomas Stamford Raffles, has been replicated (Idawati 2010). Referencing Singapore has also generated significant urban development cooperation between Singaporean and Chinese state-owned enterprises, and business opportunities for Singapore-based architectural and urban planning consultancies (Chua 2011: 29-54). Meanwhile, Singapore is studying the public transport system of Hong Kong; Hyderabad is studying the infrastructure development of Shanghai; and Bangalore has itself become a reference point for cities aspiring to attract investment in high-tech industries (Goldman 2011). ${ }^{1}$

A third area where inter-referencing between Asian locations takes place is in the regionalisation of the media and popular culture. There is a historically wellestablished network of production, distribution and consumption of Chineselanguage pop music, opera and films within the ethnic-Chinese-dominated locations of China, Taiwan, Hong Kong and Singapore and in other smaller 'diasporic' ethnic-Chinese communities throughout Southeast Asia. At different

1 For more cases of inter-referencing of Asian cities, see the other essays in Roy and Ong (2011). 
periods in the past, Japanese film and pop music made forays into this network and achieved intermittent popularity for some singers and actors. In the 1990s, Japanese television dramas became a staple of audiences throughout East Asia. This success encouraged the Korean television industry, where dramas are the mainstay of daily programming, to learn from the high-quality production values of Japan and to actively export its own dramas regionally. As a consequence of the liberalisation of the media industries in Taiwan and China, satellite and cable stations in these locations were quick to import Japanese and Korean dramas to fill the excess slots in their programming schedules, first by pirating the programs and later by legally importing them. Imported Japanese and Korean programs are either dubbed or translated for redistribution throughout the Chinese-language media network, thus expanding the market for producers and their importers. The creation of a regional transnational audience has led to tentative attempts at co-production between one or more locations, involving actors and other production professionals from different places, to produce 'pan-East Asian' films and dramas with the hope of expanding the audience and market for such products. All of these processes - concentrated in the past two decades - have resulted in a loosely integrated regional media/cultural industry in East Asia. As for the regional transnational audiences, different Asian locations seen on television have become locations of cultural interest, promoting intra-Asian tourism and cultural exchanges. Locations that show evidence of greater development in terms of capitalist consumer modernity have come to represent aspirational futures for audiences in less-developed economies and, for locations that are coeval in development, examples for mutual cultural learning and emulation. On the academic front, these developments have engendered a new field of individual and collaborative research in East Asian popular culture (Chua 2012; Chua and Iwabuchi 2008).

The first of the above three instances of inter-referencing is an example of Japan's long-standing tendency to place itself as 'being in but not a part of Asia', by positioning itself as the leader taking along the rest of Asia. This tendency contributed to Japan's imperialist ambitions, expressed in regional aggression in the Pacific War. Unfortunately, such illiberal tendencies persist in some segments of Japanese society (Iwabuchi 2002a: 547-73). The second instance is a straightforward attempt at reproducing a model locally or, more importantly, of invoking another Asian location as a provocation to local government to act towards an aspirational future. The last is of integration of the region through working out the historical and cultural differences that not only characterise the region but also often act as obstacles to regional collaboration. Beneath the noisy and quarrelsome international political discussions between the East Asian neighbours, an integrative cultural exchange network is being developed. 


\section{Shifting frames of comparison}

Instances of inter-Asian referencing exemplify a significant epistemological shift in the generation of knowledge in Asia. In 200 years of development of capitalism and liberal democracy in Euro-America, many kinks have been ironed out along the way. For example, the process of the enfranchisement of all citizens passed through stages of discrimination and restrictions on individuals of different gendered and racialised positioning. The exploitation of labour has a long history - from the horrendous conditions of early industrialisation in the seventeenth century to the institutionalisation of postwar social democracy and other forms of welfarism. In contrast, rapid capitalist development is a postwar phenomenon in most parts of Asia, with the exception of Japan. Asian nations, with few exceptions, are still struggling to institutionalise some, if not most, aspects of electoral democratic politics in political and economic governance. With such great historical temporal distance, in any comparison of Asia with Euro-America, the Asian location will (not unexpectedly) come up short on a whole constellation of political and economic dimensions. That is why, in an Asia-Euro-America comparison, Asia is permanently in a state of catch-up, as Chakrabarty (2000) puts it, placing Asia in the 'prison house of history'.

In contrast, all the nations in Asia have emerged from either imperial dynasties, such as China and Japan, or colonialism after World War II. In most cases, democratic political processes were introduced to the newly independent Asian nations only after World War II. With the exception of Japan, the first wave of capitalist industrialisation was not initiated in Asia until the 1960s. This was the case in South Korea, Taiwan, Hong Kong and Singapore, followed subsequently by others in Southeast Asia, with the most recent entrants being the post-socialist economies of China, Vietnam and, to a significant extent, India. The span of time between the early movers and the later entrants into electoral democratic politics and economic industrialisation is no more than three decades. The success or failure of any state in instituting democracy and capitalist economic growth remains within the horizon of imaginable possibilities for the other states in the region. Thus, as Chen (2010) suggests, inter-referencing Asia shifts the frame of comparison to a temporally coeval, horizontal plane between locations in Asia - in contrast with the temporally and historically unequal comparison of Europe and Asia. 


\section{Comparative political economy}

Let us take political development as an illustration. In the postcolonial states in South and Southeast Asia, with the possible exception of India, immediate attempts after independence to institutionalise electoral democratic politics generally failed, often resulting either in dictatorship, as in South Korea, the Philippines and Indonesia, or in some less than fully democratic form of electoral politics, such as the one-party-dominant state of Singapore or the Malay-first multi-party alliance in Malaysia. In the case of the respectively post-dynastic and postcolonial communist states of China and Vietnam, very limited villagelevel elections have been instituted only since the 1990s. Furthermore, most of these nations are still struggling with different modes of repressive government. There is also endemic corruption by self-interested politicians and other members of the elite, taking turns to put their hands in the nation's till under the veil of 'democratic' elections, as electoral processes become the sine qua non to claims of being democratic, regardless of the substance. Political education of the citizenry in modern democracy is in many ways still in its infancy. The comparative analysis of these Asian examples holds significant lessons for understanding the differences and the complexities of trajectories within the region. ${ }^{2}$ By contrast, there is an analytic stance that holds Western liberal democracy as the endpoint of democratic development and thus as the 'critical' mirror that, unsurprisingly, constantly finds Asian examples wanting. The result is ideologically laden labelling of the Asian examples as 'authoritarian', 'illiberal' (Bell et al. 1995), 'electoral autocracy' (Diamond 2002) or, perhaps more generously, 'semi-democratic' (Case 1993). Each of these comparisons is driven, implicitly or explicitly, by an ahistorical teleology of 'sameness', towards an endpoint already achieved by the contemporary West, without pausing to ask whether Asia wants to be the same as the West.

In the economic dimension, the relatively temporally coeval patterns of economic development of Asian countries can definitely be fruitfully compared with one another. Within the generalised concept of the 'developmental state', the current comparative configuration of the different states in East Asia can be shown to be largely determined by the different ways that state and capital were conjoined at the early stages of export-oriented industrialisation in each country. The Korean government, for example, first transferred the industries that were handed over by the defeated Japanese colonial administration to the few extant Korean industrial families and subsequently provided significant financial advantages to encourage the family capitalist class to spearhead export-

2 See the special issue of Democratization (2007), 'Beyond hybrid regimes', guest edited by Garry Rodan and Kanishka Jayasuriya. 
oriented industrialisation, creating what are now known as the 'chaebols' (comparable to the Japanese zaibatsu or keiretsu companies). Since the 1980s, these families have effectively sustained their dominance in the respective chaebols with a system of complicated cross-share ownership and executive positions, as the chaebols as a group progressively monopolised the national economy. Consequently, they have attracted public criticism for the corrupt and illegal manipulation of company finances for selfish family benefit and for stifling domestic entrepreneurial initiatives by acquiring successful business startups or setting up competing companies and forcing start-ups out of business. By the end of the 1990s, chaebols had become political liabilities for all elected presidents, with each promising reform of the system. The chaebols, however, have grown to be global corporations and have become independent of the state; they have become a relatively autonomous interest group that actively lobbies for their preferred electoral candidates. Dependency on electoral support has blunted the politicians', and hence the state's, ability to act against the chaebols. ${ }^{3}$

In Singapore, by contrast, at the point of launching industrialisation, there were no industrial capitalists. This forced the newly elected, independent government to rely on foreign capital investment to power its industrialisation. In enterprises where foreign capitalists were risk-averse, the state established its own corporation to take up the business. The state also invested heavily in so-called natural monopolies rather than transferring such enterprises to private capital. The result is a state with a high degree of economic autonomy; not only is it not dependent on local capitalists, it is also able to continue to chart the direction of its industrial policies. Meanwhile, its investments in state enterprises have reaped huge returns, as many of these enterprises have become successful globalised corporations, with the Singapore government continuing as the majority shareholder and manager. Finally, the accumulated profits generated by state enterprises have been used to set up a sovereign wealth fund that invests globally on behalf of the Singapore state - a process that is being emulated by emerging economies, such as China, when they are able to do so.

\section{Asian models}

Perhaps the most practical aspect of referencing Asia is in how locations in the region are trying to learn from one another's experiences, to take lessons from ostensibly successful examples and to find so-called best practice in different aspects of social, economic and political governance. A significant example is the way China, the biggest country in Asia, studies Singapore, one of the smallest, for potentially useful lessons in many aspects of governance, in spite 
of the vast difference in scale. Singaporean architecture and urban planning consultants, for example, in both private and government-linked companies, are receiving large urban planning contracts in different cities in China, starting with the Suzhou Industrial Park outside Shanghai-the first cooperation between state-owned companies and relevant state authorities. Since 1992, this model of cooperation between the two countries has multiplied to include several other large urban planning projects, including the Tianjin Eco-City Project and the Guangzhou Knowledge City Project. The Nanyang Technological University in Singapore runs a 'Chinese mayor' program for would-be mayors and other city bureaucrats from China to learn about the urban management systems of Singapore. Finally, in 2012, the state-owned China Central Television began making a 10-part documentary series on different aspects of Singaporean life, including the political system, to be aired in China as public education. The reason for China's referencing of Singapore is obvious. China would like to replicate, if possible, despite the difference in scale, Singapore's success in capitalist development while maintaining a non-corrupt, elected single-partydominant state power with a high degree of electoral popularity, and hence legitimacy to govern. Apart from China, Singapore has regularly been mentioned in other Asian locations, including the newly independent Timor-Leste, as an example for emulation, and as an icon of successful economic development and improvement of material life of its citizens - rather than for its anti-liberal polity under the long-ruling People's Action Party (PAP). Other examples of Asian references can be found: Shanghai as a model for Hyderabad; and Malaysia as a model for Islamic capitalist development.

From an academic angle, what is interesting about 'modelling' Asia is the conceptual and critical research this process might generate. First, such modelling is a process of knowledge and expertise transfer, which involves a significant amount of intergovernmental traffic, which shapes regional international relations. Second, processes and practices of governance are developed in a particular location as consequences of local historical contingencies and are often conceived and executed as interconnected activities. In the process of transfer across space and time, this historically determined assemblage of practices is disassembled and only selective aspects are picked up and applied in the new environment. The result is often contrary to the achievements of the original model. Third, while there are instances in which the modelling process has led to mimicry, more often than not the model is evoked rhetorically as a trope to criticise local authorities and, hopefully, to provoke them into greater accountability and accomplishment in bettering local citizens' lives. We could paraphrase, for example, the late Deng Xiaoping (1904-97), initiator of the marketisation of the Chinese economy, who exhorted Chinese bureaucrats to look to Singapore because 'they are doing something right and we ought 
to be able to do better' (see further Fook 2010: 175). Each of these areas of intergovernmental, commercial and political activities that resulted from referencing Asia constitutes a site of theoretical and applied research.

\section{Pop-culture regionalism}

Globally, there is no doubt that the United States, especially Hollywood, is the dominant producer and distributor of transnational popular culture. Juxtaposed against this, however, is the emergence of regional networks of production, distribution and consumption of popular culture in Asia. This has been facilitated by new communication technologies and the liberalisation of the once nationalised or tightly controlled media industries in the region. Each geographically identifiable region has its own networks. There is usually one dominant player (some more than others depending on the relative economic conditions among the member countries in a region) in each network. This is the primary producer and exporter of the pop culture that is distributed, legally or otherwise, and consumed regionally. In the case of South Asia, the dominant player is Bollywood (Rajadhyaksha 2003). In mainland Southeast Asia, Thai pop culture is well received in Laos and areas bordering Myanmar (Jirattikorn 2008) and Cambodia. In island Southeast Asia, among the Muslim/Malaylanguage communities, Indonesia is marginally dominant; and in East Asia, the regional network is much more complicated, with shifting dominant players according to different popular culture genres (Chua 2012). Such networks might peripherally exceed their respective regional boundaries and appear in other parts of Asia, but they do not reach the global market, despite frequent claims by the producers and other grandiose claims infused with nationalism. Despite occasional breakthroughs to the global market, more than 95 per cent of Korean pop culture exports are destined for East Asia, with Japan taking more than 80 per cent and the rest going to Taiwan, Hong Kong and China, and, via these three locations, to the rest of the small diasporic ethnic-Chinese communities around the world. What is interesting about these regional popular culture networks is that they exist beneath the noisy international relations among the quarrelling nations who are constantly provoking antagonism over historical events to bolster nationalism. As armed conflicts increasingly become something to avoid, competition between the quarrelling nations has also led to the export of popular culture as an instrument of 'cultural diplomacy' ${ }^{4}$ Of these regional networks, the one that has received the most academic investigation is the East Asian Pop Culture Network. The political, economic, social and

4 There is a significant body of literature on East Asian popular culture, which includes films, pop music and television dramas. For a comprehensive survey of this literature, see Chua (2012). 
cultural processes in the transnational production, distribution and reception/ consumption of regional popular culture investigated in the East Asian Pop Culture Network can readily serve as points of reference for the other regional networks in Asia.

\section{Concept formation}

Scholars of Asia, especially social scientists, have often trimmed local complexities to fit into existing concepts whose origin in Euro-American studies has been erased, with the concepts apparently being universalised. The point here is not to reject such concepts out of hand simply because they are generated in the West, nor to deny scholars in the West the right to theorise with whatever empirical material they have to hand. The problem is one of adequate conceptualisation and understanding of the local. A concrete example will clarify the issue.

One of the common practices among Huaren (ethnic-Chinese) in Singapore is for working children, including those married with families of their own, to voluntarily give money to their parents monthly, even when the parents are not in need, as is the case in most middle-class families. There are no written agreements, of course, and the quantum given is flexible. Locally, it is generally regarded as an expression of filial piety, of Confucianism as a 'little' tradition. One young Scandinavian scholar radically simplified this practice as a 'contract' in English. Contract, unfortunately, implies a formal legal financial transaction, suppressing completely the symbolic and emotive complexities that are embedded in the practice, including the self-worth and self-image of not only the children but also the parents. The scholar was well aware that this was an unhappy choice of terms. During an oral presentation, the scholar freely admitted, and apologised for, the inadequacy of the concept of contract. This unfortunate slippage is, perhaps, the result of focusing too much on the financial aspects of the idea of filial piety because giving money to parents monthly is the most concrete and therefore the most-mentioned activity that materialises the fuzzy and complex concept for young Chinese research respondents. ${ }^{5}$ This is not an uncommon example; the messiness of the local empirical material has been trimmed to fit awkwardly into an existing concept developed elsewhere.

\footnotetext{
5 This overemphasis on the financial aspect of filial piety is evident in her book, where the term 'contract' is also used (Goransson 2009: 103).
} 
Concepts are shorthand ways of representing an inexhaustible volume of descriptive empirical information. Each concept is a decontextualised, abstracted lexical item with its own contextual origin and a history that has been suppressed or erased. Consequently, the existing concept never captures new empirical material without slippage, distortion, reduction or excess. Modification is unavoidable if a concept is to be used in a new context. Additionally, working in different language contexts in Asia, local practices often cannot be represented by existing concepts, as seen in the example above. Local concepts are not always translatable into English terms without severe loss of richness. Faced with both conditions, one should preserve the richness of the local and develop concepts that are adequate to its complexity, including, if necessary, by using local terminology. Again, a concrete example will clarify.

A Korean cultural studies scholar, trained in Australia, in her analysis of the mode through which the Korean pop culture industry exports its products internationally, uses the term 'mugukjeok' to characterise what makes their products globally mobile. The term has its equivalents in both Chinese (无国籍 / wu guo ji) and Japanese (無国籍 / mukokuseki). This scholar credited Koichi Iwabuchi with introducing this term in his analysis of Japanese media culture exports (Jung 2011: 17-18). Western scholarly attention to Iwabuchi's (2002b) work, however, has picked up the term 'culturally odourless' for Japanese cultural exports as opposed to Jung's appropriation of the term mukokuseki. The reason is quite simple.

In English, mugukjeok would likely be translated into 'stateless', a common negative term in the politics of citizenship. A stateless person is one without citizenship, and therefore no civil rights, in a world constituted by nationstates. The term mukokuseki therefore does not denote transnational boundary crossing as a positive value; hence, the preference for the term 'odourless'. However, Jung has nuanced the term in Asian languages in the context of cultural exports by turning 'statelessness' into a positive quality of mobility, of being unbound by nations, erasing the reference to nations, as in the term 'transnational'. For me, this is a better term to characterise culture that travels than any 'trans' words in English. This is an example of what I think of as the process of new concept formation that is a consequence of inter-Asia referencing. In this instance, the proximity of the Chinese, Korean and Japanese languages, which contain traces of the past, and maybe even a continuing, shared culture, has facilitated the development of the concept. ${ }^{6}$ Such shared cultural affinities,

6 The use of compounds derived from Chinese characters in these East Asian languages facilitates such inter-referencing. 
however, are not a necessary condition: a new concept could be formulated in the English language in one Asian location and provoke nuanced resonance in another.

\section{Conclusion}

I have demonstrated above that one consequence of the rise of Asia in global capitalism is the stimulation of concrete and practical instances of one location in Asia using another as a reference point for its own ongoing social, economic and political governance. Following such concrete activities, there has been a similar shift in Asian studies, especially among scholars based in Asia, to call attention to the process of referencing Asia. This has resulted in an epistemological shift from the temporally hierarchical Asia-Euro-America comparison, which places Asia permanently in a position of 'catch up', to one of a horizontal comparison of inter-Asian locations among relatively comparable equals, thus generating different forms of knowledge and, perhaps, knowledges of greater utility for Asian development, intellectual and otherwise. The shift to inter-Asia references also engenders an opportunity for the development of new concepts, facilitated by regional language affinities and, perhaps, deeper structures in shared culture that still resonate in contemporary capitalist life.

Such inter-Asia referencing, however, is not and should not be the end of the process. There is often a tendency among 'local' scholars to emphasise the 'non-transferability' of local concepts, usually as a rearguard strategy to preserve the uniqueness of the local. This is also because of an abhorrence of 'universals' - a sentiment grounded in a postcolonial suspicion of universalisation as a mode of subjugation of the colonised. While such postcolonial cautions are necessary, one should also realise that, ironically, to overemphasise the nontransferability of local concepts is to condemn local scholarship to the fate of being 'unique' and, therefore, 'interesting' in an exotic way, but ultimately, irrelevant to others. ${ }^{7}$ The universalisation of concepts is necessary if the knowledge is to be communicated across spatial and cultural boundaries; one might say that universalisation is the logic of knowledge production and there can be no provincialisation of knowledge. Scholars in Asia, therefore, have a responsibility to situate local scholarship as part of the global archive and to add universalising concepts developed in Asia.

7 As one who writes often on Singapore, I am constantly faced with such comments regarding the 'uniqueness' of Singapore because it is an island nation or a city-state and, therefore, holds no lessons for 'normal' countries. 


\section{References}

Bell, Daniel A., Brown, David, Jayasuriya, Kanishka and Jones, David Martin. 1995. Towards illiberal democracy in Pacific Asia. London: Macmillan.

Case, William. 1993. Semi-democracy in Malaysia: Withstanding the pressures for regime change. Pacific Affairs 66(2): 183-205.

Chakrabarty, Dipesh. 2000. Provincializing Europe: Postcolonial thought and historical difference. Princeton, NJ: Princeton University Press.

Chang, Kyung-Sup. 2011. South Korea under compressed modernity: Familial political economy in transition. London: Routledge.

Chen, Kuan-Hsing. 2010. Asia as method. Durham, NC: Duke University Press.

Chua, Beng Huat. 2011. Singapore as model: Planning innovations, knowledge experts. In Ananya Roy and Aihwa Ong, eds. Worlding cities: Asia experiments and the art of being global. Chichester: Wiley-Blackwell.

Chua, Beng Huat. 2012. Structure, audience and soft power in East Asian cinema. Hong Kong: Hong Kong University Press.

Chua, Beng Huat and Iwabuchi, Koichi. eds. 2008. East Asian pop culture: Analysing the Korean wave. Hong Kong: Hong Kong University Press.

Diamond, Larry. 2002. Thinking about hybrid regimes. Journal of Democracy 13(2): 21-35.

Fook, Lye Liang. 2010. Singapore's involvement in China's reform. In John Wong and Bo Zhiyue, eds. China's reform in global perspective. Singapore: World Scientific Publishing.

Gaonkar, Dilip Parameshwar. ed. 2001. Alternative modernities. Durham, NC: Duke University Press.

Goldman, Michael. 2011. Speculating in the next world city. In Ananya Roy and Aihwa Ong, eds. Worlding cities: Asia experiments and the art of being global. Chichester: Wiley-Blackwell.

Goransson, Kristina. 2009. The binding tie: Chinese intergenerational relations in modern Singapore. Honolulu: University of Hawai'i Press.

Hoffman, Lisa. 2011. Urban modeling and contemporary technologies of citybuilding in China: The production of regimes of green urbanisms. In Ananya Roy and Aihwa Ong, eds. Worlding cities: Asia experiments and the art of being global. Chichester: Wiley-Blackwell. 
Idawati, Dyah E. 2010. Imagining Surabaya's new image: to be another Singapore? Global urban frontiers: Asian cities in theory, practice and imagination workshop. September 8-9, Asia Research Institute, National University of Singapore.

Iwabuchi, Koichi. 2002a. Nostalgia for a (different) Asian modernity: Media consumption of 'Asia' in Japan. positions: east asia cultures critique 10(3): 547-73.

Iwabuchi, Koichi. 2002b. Recentering globalization: Popular culture and Japanese transnationalism. Durham, NC: Duke University Press.

Jirattikorn, Amporn. 2008. Pirated transnational broadcasting: The consumption of Thai soap operas among Shan communities in Burma. Sojourn 23(1): 30-62.

Jung, Sun. 2011. Korean masculinities and transnational consumption: Yonsama, Rain, Oldboy and K-pop idols. Hong Kong: Hong Kong University Press.

Nair, Janaki. 2005. The promise of the metropolis: Bangalore's twentieth century. New Delhi: Oxford University Press.

Ong, Aihwa. 2011. World cities, or the art of being global. In Ananya Roy and Aihwa Ong, eds. Worlding cities: Asia experiments and the art of being global. Chichester: Wiley-Blackwell.

Ozawa, Terutomo. 2005. Institutions, industrial upgrading, and economic performance in Japan: The 'flying-geese' paradigm of catch-up growth. Northampton, MA: Edward Elgar.

Rajadhyaksha, Ashish. 2003. The 'Bollywoodization' of the Indian cinema: Cultural nationalism in a global arena. Inter-Asia Cultural Studies 4(1): 25-39.

Rodan, Garry and Jayasuriya, Kanishka. 2007. Beyond hybrid regimes. Democratization 14(5): 773-94.

Roy, Ananya and Ong, Aihwa. eds. 2011. Worlding cities: Asia experiments and the art of being global. Chichester: Wiley-Blackwell. 
This text is taken from The Social Sciences in the Asian Century, edited by Carol Johnson, Vera Mackie and Tessa Morris-Suzuki, published 2015 by ANU Press, The Australian National University, Canberra, Australia. 